\title{
La décima y la oralidad
}

\section{Popular poetry and oral tradition}

\section{Giancarla Di Laura ${ }^{1}$}

Universidad SISE, Lima, Perú

\section{RESUMEN}

Este trabajo estudia en detalle la aparición de este poeta popular afroperuano que a través de su obra literaria proyecta un comportamiento que tiene que ser cambiado. Usando el humor en la configuración discursiva este poeta ofrece una enseñanza moral a lo largo de sus textos. Para que un texto se vuelva popular y pertenezca a un imaginario social debe tener ciertas características. Estos tres rasgos, el humor, la musicalidad y la identificación, harán que el poema perdure para siempre. Asimismo, la estructura ayuda a que este texto pase de generación a generación a través de la repetición y de la memoria. El poeta afroperuano Nicomedes Santa Cruz fue uno de los primeros que cultivó la décima espinela. Él es uno de los más conocidos poetas y escritores que han publicado sobre la tradición negra en el Perú.

\section{PALABRAS CLAVE}

Poesía popular, décima, escritor afroperuano

\section{ABSTRACT}

This paper studies in detail the appearance of this popular poet who throughout his work, he projects social behavior to be changed. Using humor in the configuration of its discourse this writer gives a lesson to the reader. In order to a text to become popular and to remain the social imaginary it has to have certain rules. The three basic characteristics that makes a poem perdurable is because the use of humor, musicality and identification. Also, the

1 Directora de Investigación de la Universidad SISE. PhD en Lenguas Romances por la Universidad de Virginia. 
structure helps the text belong to the social imaginary where these poems will be repeat it generation by generation. The Afro Peruvian Nicomedes Santa Cruz is one of the first «decimeros» (popular poets that write a specific type of rime) where this sort of text will remain in the tradition because of its rhythm, and the story that narrates. Santa Cruz is one of the most well known writers that works on different approaches on Afro Peruvian culture.

\section{KEYWORDS}

Popular poetry, characteristics of a text, Afro Peruvian writer

\section{La décima y la oralidad}

Generalmente, un texto trasciende en el imaginario social de una región debido a su popularidad y a la repercusión que tiene en dicha sociedad. A través de los años, la repetición de dicho relato pasa a través de generaciones y de clases sociales mediante una cadencia o una musicalidad que se vuelve familiar. Especialmente, una de las medidas más cómodas para aprender y memorizar un texto es la del verso octosílabo, cuya estructura comprende la décima. Es decir, la décima es una estrofa compuesta de diez versos octosílabos.

En su libro Literatura oral o la literatura de tradición oral, Gonzalo Espino nos afirma sobre la conceptualización de las literaturas orales: «La noción canónica de literatura oral es que se encuentra vinculada al folclore». El folclore que es la manifestación cultural y tradicional de un pueblo, es lo que en este caso en particular profundizaremos a medida que veamos como la oralidad repercute en ciertos textos que propician la musicalidad para que así se grabe en el imaginario social.

El propósito de este trabajo consiste en estudiar la literatura oral que el autor afroperuano Nicomedes Santa Cruz (1925-1992) escribe y declama, abarcando un nuevo público y volviéndola más popular a través de sus décimas. En su emblemático texto «La pelona», Santa Cruz revitaliza una forma tradicional y la vuelve popular en todos los sectores educacionales. Esta décima se populariza más a través de una serie de elementos que hacen que la vigencia de la literatura oral —la declamación — sirva y beneficie a la memoria popular.

Asimismo, Espino nos explica que el folclore «estudia desde entonces la cultura de los alrededores, de los no letrados, las culturas primitivas, lo exótico» (2015, p. 18). De esta manera, notamos cómo las décimas de Santa Cruz se vuelven famosas, ya que son estudiadas en todos los 
ámbitos educativos, pero también por su estructura y porque cumple con tres factores que se distinguen: 1) la musicalidad, que sirve para que, como una canción entonada y rítmica, se repita a través de las generaciones, 2) la historia, es decir, el lenguaje usado para configurar el discurso poéti$\mathrm{co}$, tiene que ser de preferencia regional, algo que interese y que capte la atención de un público que se identifique con estos comportamientos; y esto nos lleva finalmente al punto: 3) el humor, que a mi parecer es el elemento básico por el cual se capta la curiosidad de un público que se distingue por compartir la risa y no solamente el Ilanto.

El autor afroperuano ha publicado una variedad de textos, pero los que se prestan para ser declamados o recitados suelen ser sus décimas, las cuales no solamente hablan de un tema, sino que recogen algún tipo de comportamiento social por el cual se critica una actitud o se reflexiona sobre una acción. Para esto, Santa Cruz utiliza la estructura de la décima espinela, que comprende 10 versos octosílabos cuya rima es abbaaccddc. No olvidemos que la décima es conocida también como espinela en homenaje a su supuesto inventor, el poeta Vicente Espinel, quien a fines del siglo XVI elaboró esta forma basándose en la métrica tradicional popular española, hecha en octosílabos. La estrofa recibió amplia aceptación por la facilidad con que puede recitarse y musicalizarse, hasta hoy. En la siguiente estrofa, notamos este tipo de rima:

Te cambiaste las chancletas

por zapatos taco aguja,

y tu cabeza de bruja

la amarraste con peinetas.

Por no engordar sigues dietas

y estás flaca y hocicona.

Imitando a tu patrona

has aprendido a fumar.

Hasta en el modo de andar

cómo has cambiado, pelona.

La cadencia rítmica se permite notar a través del tipo de décima que es, espinela. Asimismo, la musicalidad que denota el lenguaje a través de la estructura de la rima: chancletas, peinetas y dietas; aguja y bruja; hocicona, patrona y pelona; $y$, finalmente, fumar con andar. Todo ello cumple con la forma rítmica. Es debido a la repetición constante de este tipo de estrofa que permite la perdurabilidad en ese imaginario social, que sin realmente referirse a un momento histórico exacto, representa un comportamiento que no es auténtico, sino que calza con los presupuestos establecidos por una línea hollywoodense de los años 50 y 60 . 
La historia relatada sobre una mujer afroperuana que usa ornamentos inservibles para ser vista como una mujer modelo, dictada por los parámetros sociales, proyectan una imagen grotesca de la mujer afroperuana.

Usas reloj de pulsera

y no sabes ver la hora.

Cuando un negro te enamora

le tiras con la cartera.

¡Qué...! ¿También usas polvera?

permite que me sonría

¿Qué polvos se pone usía?:

¿ocre? ¿rosado? ¿rachel?

o le pones a tu piel

cisco de carbonería.

Obviamente, el lenguaje ayuda a caracterizar el comportamiento falso de esta mujer, hasta pretender cambiar su color de piel con maquillajes para blanquearse. El lenguaje que utiliza muchas veces es coloquial y permite darle un tono conversacional muy adecuado para la generación a la cual pertenece. Asimismo, Santa Cruz, usa expresiones o relatos que pertenecen también a cuentos populares cuyor orígenes se basan en la literatura oral. La expresión «iFrancica, botá frifró que son comé venarique...!» remite a un cuento existente en la cultura afroperuana. Particularmente, estos dos versos relato sobre un negro angola y su mujer, quien le estaba cocinando frijoles, mientras que su marido estaba trabajando en el campo. Al regreso del algodonal, el marido se percata sobre la presencia de un venado amarrado de un árbol, y decide llevárselo. Cuando llega a su casa ve a su amada preparando frejoles, y él le dice que los bote, «Francica, botá frifró», porque ese día comerán venado, «que son comé venarique...!». Luego de insertar Santa Cruz en sus décimas relatos populares, sus décimas se popularizan más y más.

El humor se capta desde el principio de la décima, ya que es un elemento fundamental en la configuración discursiva del poema. Al usar el humor, el autor corta la distancia con el lector o público y, por medio de la risa, permite que exista una confabulación. El humor siempre une e identifica, más aún cuando se usan expresiones regionales, como «jeta» y «huachafería». Estos dos términos pertenecen a la jerga peruana, «jeta» en lugar de boca y «huachafería», la actitud ordinaria que optan algunas personas para destacar en un medio. Asimismo, encontramos repetidas veces que la décima proyecta una lección o temor, en el sentido que previene sobre alguna acción emitida: 
Perdona que te critique, y si me río, perdona.

Antes eras tan pintona con tu traje de percala y hoy, por dártela de mala te has vuelto una negra mona.

Finalmente, siempre se destaca una sugerencia o un consejo sobre qué hacer o seguir para dejar de ser esa «negra huachafa» que ha capturado un comportamiento ajeno a su realidad, el cual la hace ver como una persona falsa e ilegítima. Por eso, al final se encuentra una sugerencia de la voz poética hacia la «Pelona».

Deja ese estilo bellaco, vuelve a ser la misma de antes.

Menos polvos, menos guantes, menos humo de tabaco.

Vuelve con tu negro flaco que te adora todavía Y si no, la policía te va a llevar de la jeta por dártela de coqueta con tanta huachafería.

Entonces, recopilando las ideas expuestas notamos que la relación entre la décima y la literatura oral se encuentra bajo tres principios básicos que ayudan a perdurar en un imaginario social: musicalidad, lenguaje y humor. Estos elementos permiten que, de generación a generación, la memoria recuerde este tipo de décima o poema que comparte un comportamiento espurio para que las futuras personas opten por ser auténticos y transparentes en su devenir cotidiano. La estructura de la décima espinela, por su cadencia y musicalidad, permite perdurar en la memoria colectiva de una región. El uso de un lenguaje coloquial le da toques regionales y, a la misma vez, humoriza la secuencia poética para que sea declamada o actuada en muchas ocasiones. Finalmente, el humor tan perenne en las construcciones poéticas de Nicomedes Santa Cruz deja toques íntimos a un lector o público atento.

Otra décima que sigue con los mismos parámetros es el caso de «La escuelita». Esta décima se hizo muy popular a todo nivel, desde el colegio hasta en recintos de diversión, como las peñas criollas, entre las más destacadas la de Porfirio Vásquez, quien influenció mucho a Santa Cruz. Desde la irrupción del estribillo notamos el humor sarcástico que existe en la poesía: 
A cocachos aprendí

Mi labor de colegial

En el colegio fiscal

Del barrio donde nací

Es decir, desde el inicio la voz poética se identifica como un hombre afroperuano quien no supo aprovechar el tiempo. En la primera estrofa nuevamente con la décima espinela encontramos la musicalidad en el ritmo de las palabras.

Tener primaria completa

Era raro en mi niñez

(nos sentábamos de a tres

En una sola carpeta).

Yo creo que la palmeta

La inventaron para mí,

De la vez que una rompí

Me apodaron mano'e fierro

Y por ser tan mataperro

A cocachos aprendí

La inserción de términos coloquiales como «mano'e fierro» y «mataperro» inscriben a esta décima en un sector popular con raíces pícaras. Son usadas para darle un toque de familiaridad, y así el lector o público pueda identificarse y entablar una relación más íntima. Nuevamente nos encontramos con la décima espinela, cuya rima perfila ritmo y cadencia: «completa, carpeta y palmeta», luego «niñez con tres», «mí con rompí y aprendí», y, finalmente, «fierro con mataperro». Esta musicalidad sirve para que se aprenda más fácil el texto. La voz poética en la primera estrofa comenta sobre la situación que tenía esta persona en particular y que debido a su comportamiento tuvo que vivir ciertos castigos.

En la segunda estrofa notamos que la voz lírica describe su vida escolar, cuyo rendimiento era malo. Tal vez esta décima tiene también un fin didáctico ya que nos quiere dar una lección:

Juguetón de nacimiento,

Por dedicarme al recreo

Sacaba diez en Aseo

$Y$ once en aprovechamiento

De la conducta ni cuento

Pues, para colmo de mal

Era mi voz general 
¡Chócala pa' la salida!

Dejando a veces perdida

Mi labor de colegial.

Su desempeño en el colegio es decadente, puesto que le gusta la diversión y no el estudio. Otra vez la lección que hay entre líneas en esta estrofa proyecta una metáfora de la vida, cuyo aprendizaje es «aprovechar el tiempo».

La tercera estrofa es una descripción de su vida en la escuelita. Obviamente, su comportamiento lo marca como un niño a quien le gusta jugar y divertirse.

¡Campeón en lingo y bolero!

¡Rey del trompo con huaraca!

¡Mago haciéndome la vaca!

¡Y en bolitas, el primero...!

En Aritmética, cero.

En Geografía, igual.

Doce en examen oral,

Trece en examen escrito.

Si no me soplan repito

En el Colegio Fiscal.

El uso de términos pertenecientes a la jerga coloquial peruana, como el tercer verso indica, «mago haciéndome la vaca», se utiliza para darle una familiaridad al vínculo autor-lector. Además, el discurso poético se configura con sagacidad y humor, utilizando términos específicos en un colegio y tal vez un sentimiento afín con muchos niños a esa temprana edad.

En la cuarta estrofa, Santa Cruz nos ejemplifica con una lección el no haber aprovechado el tiempo:

Con esa nota mezquina

Terminé mi quinto al tranco,

Tiré el guardapolvo blanco

(de costalitos de harina).

$Y$ hoy, parado en una esquina

Lloro el tiempo que perdí:

Los otros niños de allí

Alcanzaron nombre egregio.

Yo no aproveché el colegio

Del barrio donde nací... 
Nuevamente, una lección para enseñar y manifestar a los jóvenes escolares. Las tres características básicas se repiten: musicalidad, lenguaje afín y humor son los ingredientes para que un texto perdure a través de las generaciones.

Por medio de la composición de la décima espinela, el texto se hace más fácil de memorizar.

Es decir, a través de su cadencia y musicalidad, las palabras quedan en la memoria colectiva. Estos ritmos musicales hacen más factible que un lector atento se acuerde de ciertas palabras, para que, a través de la repetición, se puedan aprender y luego quedar en el imaginario social. Es a través de la musicalidad, el lenguaje y el humor que estas décimas son compuestas para perdurar en la sociedad y así ser parte de un corpus más auténtico. Música, lenguaje y humor se conectan para estar presentes en estas composiciones y así ser recordadas a través de las generaciones. No obstante, estas dos décimas «La pelona» y «La escuelita» siguen siendo populares, siguen siendo actuadas en los colegios para homenajes, y seguirán siendo parte de nuestra cultura a través de la literatura de tradición oral. 


\section{REFERENCIAS BIBLIOGRÁFICAS}

ESPINO RELUCÉ, G. (2015). Literatura oral: literatura de tradición oral. Lima: Pakarina.

SANTA CRUZ, N. (1960). Décimas. Lima: Juan Mejía Baca.

Recibido: julio de 2017 Aceptado: setiembre de 2017 